AGRICA: Journal of Sustainable Dryland Agriculture, 13 (2): 117-124 (2020)

ISSN-Online: 2715-4955; ISSN-Cetak: 2715-6613

DOI: https://doi.org/10.37478/agr.v13i2.747

\title{
ANALISIS KETERSEDIAAN KADMIUM DI TANAH DAN BERAS YANG TERDAPAT DI DESA DETUSOKO BARAT
}

\author{
Iswawan Redu, Charly Mutiara, Josina I.B. Hutubessy \\ Program Studi Agroteknologi, Fakultas Pertanian Universitas Flores \\ Jln. Sam Ratulangi XX Paupire, Kabupaten Ende, Nusa Tenggara Timur \\ charlyinter1988@gmail.com
}

\begin{abstract}
Analysis of the Availability of Cadmium in Soil and Rice in West Detusoko Village. Cadmium is a heavy metal that is widely found in agricultural land because of the frequent use of inorganic phosphorus fertilizers. The use of high phosphorus inorganic fertilizers is also used by farmers who cultivate rice in Detusoko Barat Village. Therefore, research has been carried out with the aim of knowing the cadmium content in paddy soil and rice and its comparison with the minimum limit of cadmium in rice and soil. This research is survey research, in which the determination of soil and rice samples using a purposive sampling method. From this method, the soil samples taken are rice fields cultivating Palembang, Bengawan and Kental rice varieties. And the rice samples taken were rice from the three varieties. The variables observed were cadmium from the soil and rice and soil $\mathrm{pH}$. The results showed that the cadmium content in Palembang rice soil was 0.015 ppm, Bengawan $0.006 \mathrm{ppm}$, and thick 0.001 ppm, while the results of the research on cadmium content in Palembang rice were $0.007 \mathrm{ppm}$, Bengawan rice was $0.008 \mathrm{ppm}$, and thick rice was $0.006 \mathrm{ppm}$. Where the cadmium content in rice is still below the minimum limit that has been set.
\end{abstract}

Keywords: Cadmium, Rice fields, Soil, Rice

PENDAHULUAN

Kadmium (Cd) merupakan logam lunak berbentuk kristal dan berwarna putih keperakan yang terletak pada Golongan II B dalam susunan periodic. Unsur Kadmium memiliki nomor atom 48 dan bobot atom sebesar 112,40. Logam $\mathrm{Cd}$ ini ditemukan dalam bebatuan Calamine dan Fosfat. Kadmium tersebar luas di lingkungan namun merupakan unsur yang jarang ditemukan di kerak bumi, dengan konsentrasi 0,1 sampai 0,5 ppm. (Nikic et al., 2009).

Konsentrasi kadmium yang cukup tinggi dapat terjadi akibat adanya aktivitas manusia. Sumber dari aktivitas manusia tersebut antara lain adalah pembakaran bahan bakar fosil, produksi besi, baja, dan logam non besi, produksi semen, pembakaran sampah, dan penggunaan pupuk fosfor (P) pada daerah persawahan (Bull S, 2010). 
Berdasarkan wawancara dengan para petani di Desa detusoko Barat diketahui bahwa petani menanam padi sebanyak dua kali dalam satu tahun yaitu pada musim kemarau dan musim hujan. Varietas padi yang dibudidayakan seperti padi bengawan, Ciheran (Palembang), Mamramon, Kentan (putih dan hitam), dan C4. Padi dibudidayakan secara konvensional dengan menggunakan pupuk anorganik seperti urea, SP-36, KCL. Proses pemupukan intensif dengan pupuk fosfor dapat menjadi sumber kadmium di dalam tanah maupun Beras. Pupuk phosphat juga ditengarai mengandung kadmium 0,1-170 ppm (Setyorini et al., 2003).

Hasil penelitian Sismiyati et al. (1993) menyebutkan bahwa kandungan Cd dalam padi di beberapa daerah berkisar antara 0,31-0,33 ppm. Kasno et al. (2000) menemukan bahwa beras di Bekasi dan Karawang mengandung Cd sampai melampaui batas maksimum yang boleh dikonsumsi. Kandungan $\mathrm{Cd}$ tanah sawah yang menggunakan air irigasi tercemar limbah industri tekstil di kawasan Rancaekek-Cicalengka, Bandung berkisar antara 0,05-0,19 ppm. Sedangkan Cd dalam jerami dan beras berkisar 0,029-0,351 dan 0,026-0,18 ppm (Suganda et al., 2002)
Kadmium bagi tanaman dapat bersifat toksik yang ditunjukkan dengan gejala khlorosis dan pertumbuhan terhambat pada tanaman (Prasad, 2009). Pencemaran logam berat pada lahan pertanian khusus nya pada tanah sawah dapat terserap oleh tanaman dan terakumulasi di bagian akar, daun, buah, maupun biji (Fang dan Zhu, 2014). Akumulasi kadmium pada tanah sawah dapat menghambat penyerapan unsur hara, menghambat distribusi fotosintat, menghambat laju fotosintesis, aktivitas enzim, meningkatkan senyawa proksida, dan dapat menyebabkan perubahan genetik pada padi. Selain itu jika padi yang sudah menjadi beras mengandung kadmium dan dikonsumsi oleh manusia maka akan menyebabkan akumulasi logam berat dalam tubuh yang menjadi penyebab berbagai macam penyakit maupun gangguan fungsi organ tubuh, (Fang dan Zhu, 2014).

Desa Detusoko Barat merupakan salah satu desa penghasil beras di kabupaten Ende dan kedepannya desa ini akan menjadi desa ekowisata yang berbasis pada pertanian ramah lingkungan. Untuk itu informasi kandungan kadmium di tanah sawah dan beras yang ada di daerah tersebut 
Redu: Analsisi ketersediaan kadmium di tanah dan beras

menjadi acuan dalam pengembangan lahan persawahan selanjutnya.

\section{BAHAN DAN METODELOGI}

\section{Tempat dan Waktu}

Penelitian dilaksanakan di Desa

Detusoko Barat, kecamatan Detusoko

Kabupaten Ende provinsi Nusa Tenggara

Timur dan Laboratorium Fakultas

Pertanian Universitas Nusa Cendana.

Waktu penelitian adalah dari Bulan Mei sampai Juli 2019.

\section{Alat dan Bahan}

Alat dan bahan yang digunakan dalam penelitian ini adalah Global Positioning Sistem (GPS) alat tulis menulis, kamera, timbangan digital, plastik, kertas label serta Spektrofotometer serapan atom (SSA). Sedangkan Bahan yang digunakan adalah Beras dan tanah sawah.

\section{Penentuan Titik Sampel}

Penentuan titik sampel menggunakan metode purposive sampling, dimana sampel diambil dengan kriteria-kriteria tertentu. Kriteria yang digunakan adalah Lahan yang selalu membudidayakan varietas padi yang sama dan menggunakan pupuk anorganik fosfor. Dari kriteria tersebut didapat tiga varietas padi yang selalu dibudidayakan yaitu Palembang, Bengawan dan Kental.

\section{Pengambilan Sampel Tanah dan}

\section{Beras}

\section{Pengambilan Sampel Tanah}

Sampel tanah yang diambil merupakan sampel tanah terganggu. Sampel tanah diambil dari sawah yang membudidayakan beras palembang, bengawan, dan padi kental. Tanah dari setiap varietas diambil sebanyak 5 titik. Setiap titik diambil tanah sebanyak \pm 500 gram, lalu tanah tersebut dikomposit. Tanah yang telah dikomposit tersebut dimasukan ke dalam plastik dan diberi label.

\section{Pengambilan Sampel Beras}

Sampel beras diambil dari sawah yang tanahnya digunakan sebagai sampel penelitian. Beras tersebut diambil sebanyak $1 \mathrm{~kg}$ untuk setiap varietas. Sampel beras yang telah diambil kemudian dimasukan ke dalam kantong plastik dan diberi kode.

\section{Variabel Pengamatan}

Variabel yang diamati dalam penelitian ini adalah kadmium di dalam tanah dan beras serta $\mathrm{pH}$ tanah.

\section{Analisis Data}

Analisis logam berat kadmium pada tanah dan beras dilakukan dengan metode spektrofotometri serapan atom (SSA) SNI 06-6989 16: 2009. Data hasil 
analisis kadmium kemudian kandungan kadmium pada beras dideskripsikan dengan cara palembang yaitu $0,007 \mathrm{ppm}$, beras dibandingkan dengan batas kristis bengawan 0,008 ppm, dan beras kental kandungan di dalam tanah dan beras.

\section{HASIL DAN PEMBAHASAN}

Hasil penelitian kandungan kadmium di dalam beras di desa Detusoko Barat menunjukan bahwa 0,006 ppm. Sedangkan hasil penelitian kandungan kadmium yang ada di dalam tanah padi palembang yaitu $0,015 \mathrm{ppm}$, tanah padi bengawan $0,006 \mathrm{ppm}$, dan tanah padi kental $0,001 \mathrm{ppm}$. Data tersebut dapat dilihat pada Tabel 1 .

Tabel 1. Hasil penelitian kandungan kadmium dalam beras dan tanah di Desa Detusoko Barat.

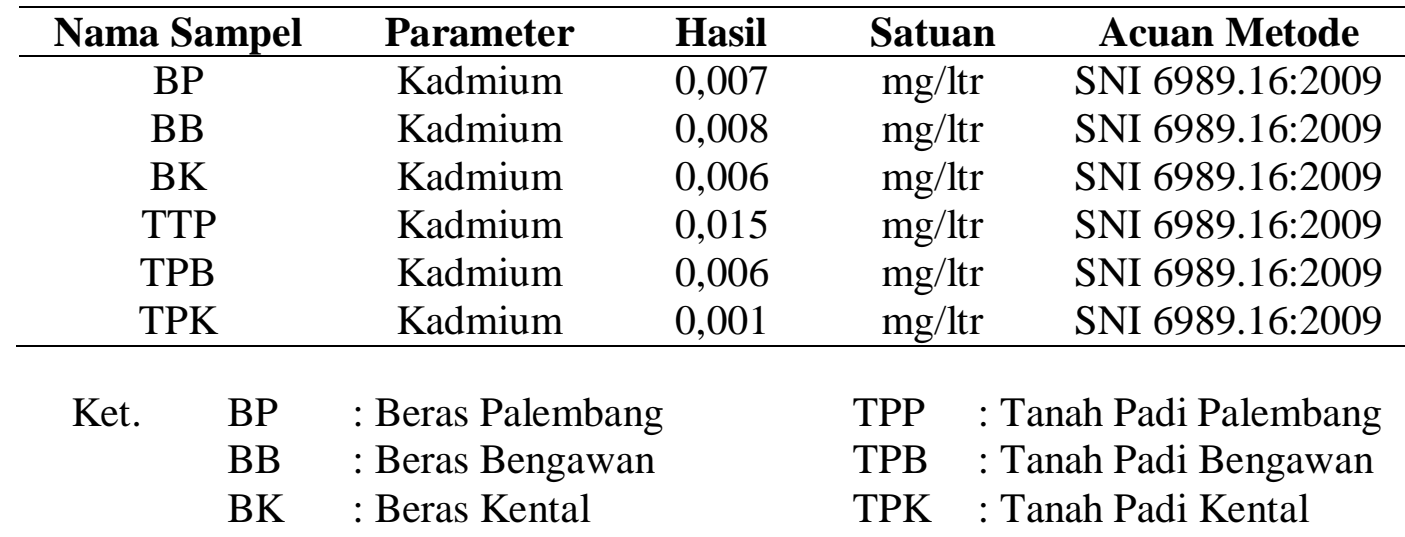

Kandungan Kadmium Dalam Tanah.

Kandungan kadmium dalam tanah di Desa Detusoko Barat sangat bervariasi. Hasil penelitian menunjukan bahwa kandungan kadmium dalam tanah padi palembang di Desa Detusoko Barat adalah 0,015 ppm lebih tinggi dibandingkan dengan tanah padi bengawan yaitu 0,006 ppm, sedangkan pada tanah padi kental 0,001 ppm lebih rendah dari tanah padi palembang dan tanah padi bengawan. Kandungan cadmium di dalam tanah tersebut masih lebih rendah dari batas kritis $\mathrm{Cd}$ di dalam tanah yaitu 0,5 ppm (Ministri of state for population environment republic of Indonesia anddolhouse University Canada. 1992). Hal ini disebabkan karena tanah di daerah tersebut mengandung $\mathrm{pH}$ tanah yang baik yaitu $6,5-7,0$.

Keberadaan kadmium di dalam tanah tidak dapat dipisahkan dari faktorfaktor lingkungan yang mempengaruhi peresapan logam berat ke dalam tanah. Faktor-faktor tersebut adalah $\mathrm{pH}$ dan 
Redu: Analsisi ketersediaan kadmium di tanah dan beras

bahan organik tanah. Kandungan kadmium di dalam tanah dengan $\mathrm{pH}$ netral cenderung lebih kecil bila dibanding pada tanah dengan $\mathrm{pH}$ asam. Kadmium lebih mobile dalam tanah sehingga lebih tersedia untuk tanaman maka lebih mudah terserap oleh tanaman (Sa'ad, 2009). Kadmium terdeteksi di semua bagian tanaman baik akar, jerami maupun beras.

Pada kondisi tanah dengan $\mathrm{pH}$ rendah, unsur kadmium akan larut dalam air tanah sehingga lebih mudah tercuci ke lapisan bawah tanah apabila turun hujan atau akan ikut terserap oleh akar tanaman pada proses penyerapan nutrien. Pada kondisi tanah dengan $\mathrm{pH}$ tinggi, kadmium akan terikat oleh koloid tanah dan bahan organik atau diendapkan dalam bentuk hidroksida, sehingga terhindar dari proses pencucian dan penyerapan oleh akar tanaman (Atmojo, 2003).

Bahan organik tanah turut mempengaruhi kandungan kadmium dalam tanah. Bahan organik akan berikatan dengan logam berat membentuk kelasi atau kelat. Kelasi bahan organik dapat mengatur ketersediaan logam di dalam tanah (Alloway dan Ayres, 1997). Faktor lain yang dapat mempengaruhi kandungan

kadmium di dalam tanah adalah kontinuitas masukan sampah, pencemaran kadmium yang berasal dari emisi bahan bakar fosil kendaraan bermotor dan bioakumulasi kadmium dalam tubuh hewan dan tumbuhan.

\section{Kandungan Kadmium Dalam Beras}

Berdasarkan hasil penelitian di laboraturium menunjukan bahwa kandungan kadmium dalam beras Palembang di desa Detusoko Barat yaitu 0,007 ppm, sedangkan beras Bengawan lebih tinggi yaitu $0,008 \mathrm{ppm}$, beras Kental lebih rendah dari beras Palembang dan beras Bengawan yaitu 0,006 ppm. Batas maksimum logamn kadmium dalam beras menurut SNI 7387:2009 sebesar 0,4 ppm. Kadmium lebih mobile dalam tanah sehingga lebih tersedia untuk tanaman maka lebih mudah terserap oleh tanaman (Sa'ad, 2009). Kadmium terdeteksi di semua bagian tanaman baik akar, jerami maupun beras. Akumulasi terbesar ada pada jaringan akar (Sa'ad, 2009).

Hal ini sejalan dengan Salt et al. (1995) dalam Suresh dan Ravishankar (2004) bahwa akar berperan penting dalam penyerapan logam berat melalui proses

Phytoaccumulation/ Phytoextraction (proses tumbuhan menarik zat kontaminan dari media 
sehingga berakumulasi di sekitarakar tanaman), Rhyzofiltration (proses adsorpsi zat kontaminan oleh akaruntuk menempel pada akar), Phytostabilisation (penempelan zat-zat tertentu pada akar yang tidak mungkinterserap kedalam batang tumbuhan. Zat-zat tersebut menempel erat/stabil pada akar sehingga tidak akan terbawa oleh aliran media), Rhyzodegradation (penguraian zat-zat kontaminan oleh aktivitas mikroba yang berada di sekitar akar) dan Phytodegradation (proses yang dilakukan oleh tumbuhan untuk menguraikan zat kontaminan yang mempunyai rantai molekul kompleks menjadi bahan yang tidak berbahaya dengan susunan molekul yang lebih sederhana yang dapat berguna bagi pertumbuhan tanaman itu sendiri). Oleh karena proses fitodegradasi ini makatranslokasi logam berat ke bagian tajuk semakin mengecil (Sa'ad, 2009).

\section{SIMPULAN}

Hasil penelian yang telah dilakukan dapat diambil kesimpulan sebagai berikut :

1. Kandungan kadmium dalam tanah padi di Desa Detusoko Barat yaitu: tanah padi Palembang 0,015 ppm, tanah padi Bengawan 0,006 ppm, dan tanah padi Kental yaitu 0,00 ppm. Kandungan kadmium dalam beras di Desa Detusoko Barat yaitu beras Palembang 0,007 ppm, beras Bengawan 0,008 ppm, dan beras Kental 0,006 ppm.

2. Kandungan kadmium di dalam tanah dan beras dari Desa Detusoko Barat masih di bawah batas kritis yang ditetapkan.

\section{UCAPAN TERIMA KASIH}

Pada kesempatan ini, penulis mengucapkan terimakasih yang sebesarbesarnya kepada semua pihak yang telah mendukung pelaksanaan penelitian ini baik dari pihak lembaga pendidikan Universitas Flores, keluarga dan lingkungan. Semoga Tuhan Yang Maha Esa memberikan berkahnya kepada kita semua.

\section{DAFTAR PUSTAKA}

Alloway BJ. 2013. Heavy Metals in Soils: Trace Metals and Metalloids in Soils and their Bioavailability. Environmental Pollution. Vol 22. 3rd Edition. Netherlands: Springer.

Anita, 2014. Kandungan cadmium di dalam tanah. Pusat Penelitian dan Pengembangan Tanah dan Agroklimat. Hlm. 203-221. Bogor.

Atmojo, S.W., 2003. Peranan Bahan Organik Terhadap Kesuburan Tanah dan Upaya Pengelolaannya. Pidato Pengukuhan Guru Besar Ilmu Kesuburan Tanah: Fakultas 
Pertanian. Universitas Sebelas Maret. Surakarta.

Bull S. 2010. Cadmium, toxicological overview. J Health Protection Agency 2 (1) : 1-15

Institut Pertanian Bogor. 2006. Bab 2 Tinjauan Pustaka. Diakses tanggal 29 me 2019.

Kasno, A., Subowo, Sulaeman, dan J. Suryono.2000. Status pencemaran Cd pada padisawah intensifikasi jalur Pantura Jawa Barat.Jurnal Ilmu Tanah dan Lingkungan 3(1). April 2000. Jurusan Tanah, Fakultas Pertanian, Institut Pertanian Bogor.

Kasno, A., Sulaeman, dan Lenita. 2000. Pengaruh pemberian jerami dan zeolit terhadap sifat serapan $\mathrm{Cd}$ pada Vertisols dan Entisols. Jurnal Ilmu Tanah dan lingkungan 3(1). Jurusan Tanah, Fakultas Pertanian, Institut Pertanian Bogor.

Kasno, A., J.S. Adiningsih, dan S. Dwiningsih. 2003. Pengaruh pemberian amelioran terhadap Kadmium tanah dan serapan Kadmium padi sawah pada tanah Vertisols dan Inceptisols. Dalam Prosiding Seminar Nasional Pengelolaan Lingkungan Pertanian. Kerjasama Loka Penelitian Pencemaran Lingkungan Pertanian, Puslitbangtanak dengan Fakultas Pertanian Universitas Sebelas Maret, Surakarta. Hlm. 191-201. Bogor.

Lestari dengan Metode Spektrometri Serapan Atom (SSA). Diakses tanggal 29 mei 2019.

Ministri of state for population environment republic of Indonesia anddolhouse University Canada. 1992. Environmental management in Indonesia. Report on soil quality standards for Indonesia.

Napitupulu, Monang. 2008. Analisis Logam Berat Seng, Kadmium dan Tembagapada Berbagai Tingkat Kemiringan Tanah Hutan Tanaman IndustriPT.Toba Pulp

Nikic et al., 2009. Estimated daily intake of cadmium by children living in the city of Niš, Serbia. J The Turkish of Pediatrics. 51 (1) : 257263.

Prasad, 2009. Biosorption of Fe(II) from Aqueous Solution using Tamarind Bark and Potato Peel Waste : Equilibrium and Kinetic Studies, Journal of Applied Sciences in Environmental Sanitation, 4(3) : 273-282.

Priyanto, Budhi \& Joko Prayitno. 2000. Fitoremediasi sebagai Sebuah Teknologi Pemulihan Pencemaran, Khususnya Logam Berat.

Sismiyati, R., I. Nasution, L. Anita, dan A.K.Makarim. 1993. Masalah pencemaran Kadmium (Cd) pada padi sawah. Disajikan dalam Simposium Penelitian Tanaman Pangan III, Jakarta/Bogor, 23 Juli5 Agustus 1993.

Suganda, H., D. Setyorini, H. Kusnadi, I. Saripin, dan U. Kurnia. 2002. Evaluasi pencemaran limbah industri tekstil untuk kelestarian lahan sawah. Dalam Prosiding Seminar Nasional Multifungsi dan Konversi Lahan Pertanian. Pusat Penelitian dan Pengembangan Tanah dan Agroklimat. Hlm. 203221. Bogor. 
AGRICA, VOL. 13, NO. 2 (2020)

Subowo, Prastowo, N. Sri Mulyani, dan J.S.Adiningsih. 1994. Pengaruh tanah Aluvial dan Grumosol tercemar $\mathrm{Pb}$ dan $\mathrm{Cd}$ terhadap produksi padi sawah. Laporan Proyek Penelitian Tanah dan Agroklimat. Bogor. 